\title{
DNA damage and oxidative stress response to selenium yeast in the non-smoking individuals: a short-term supplementation trial with respect to $G P X 1$ and $S E P P 1$ polymorphism
}

\author{
E. Jablonska ${ }^{1} \cdot$ S. Raimondi ${ }^{2} \cdot$ J. Gromadzinska $^{1} \cdot$ E. Reszka ${ }^{1} \cdot$ E. Wieczorek $^{1}$ \\ M. B. Krol ${ }^{1} \cdot$ A. Smok-Pieniazek ${ }^{1} \cdot$ M. Nocun ${ }^{1} \cdot$ M. Stepnik ${ }^{1} \cdot$ K. Socha ${ }^{3}$ • \\ M. H. Borawska ${ }^{3} \cdot$ W. Wasowicz ${ }^{1}$
}

Received: 30 July 2015 / Accepted: 17 November 2015 / Published online: 10 December 2015

(C) The Author(s) 2015. This article is published with open access at Springerlink.com

\begin{abstract}
Purpose Selenium, both essential and toxic element, is considered to protect against cancer, though human supplementation trials have generated many inconsistent data. Genetic background may partially explain a great variability of the studies related to selenium and human health. The aim of this study was to assess whether functional polymorphisms within two selenoprotein-encoding genes modify the response to selenium at the level of oxidative stress, DNA damage, and mRNA expression, especially in the individuals with a relatively low selenium status.

Methods The trial involved 95 non-smoking individuals, stratified according to GPXI rs 1050450 and SEPPI rs3877899 genotypes, and supplemented with selenium yeast $(200 \mu \mathrm{g})$ for 6 weeks. Blood was collected at four time points, including 4 weeks of washout.

Results After genotype stratification, the effect of GPXI rs1050450 on lower GPx1 activity responsiveness was confirmed; however, in terms of DNA damage, we failed to indicate that individuals homozygous for variant allele
\end{abstract}

Electronic supplementary material The online version of this article (doi:10.1007/s00394-015-1118-4) contains supplementary material, which is available to authorized users.

E. Jablonska

ewa@imp.lodz.pl

1 Department of Toxicology and Carcinogenesis, Nofer Institute of Occupational Medicine, St. Teresy 8 Street, 91-348 Lodz, Poland

2 Division of Epidemiology and Biostatistics, European Institute of Oncology, Via Ripamonti 435, Milan, Italy

3 Department of Bromatology, Medical University of Bialystok, Mickiewicza 2D Street, 15-222 Białystok, Poland may especially benefit from the increased selenium intake. Surprisingly, considering gene and time interaction, GPXI polymorphism was observed to modify the level of DNA strand breaks during washout, showing a significant increase in GPXI wild-type homozygotes. Regardless of the genotype, selenium supplementation was associated with a selectively suppressed selenoprotein mRNA expression and inconsistent changes in oxidative stress response, indicating for overlapped, antioxidant, and prooxidant effects. Intriguingly, DNA damage was not influenced by supplementation, but it was significantly increased during washout.

Conclusions These results point to an unclear relationship between selenium, genotype, and DNA damage.

Keywords Selenium $\cdot$ Selenoproteins $\cdot$ Oxidative stress $\cdot$ DNA damage $\cdot$ Gene expression $\cdot$ Selenium supplementation

\section{Background}

Selenium (Se) is an essential trace element, the importance of which for human health is indicated by the presence of at least 25 selenoproteins containing the element in a form of selenocysteine (Sec), the twenty-first proteinogenic amino acid. The unusual uniqueness of selenium stems from the fact that $\mathrm{Sec}$ is incorporated into selenoprotein polypeptide chain cotranslationally, driven by UGA mRNA codon in the presence of a specific molecular machinery, including Sec-tRNA, Sec insertion sequence (SECIS) element, and protein factors such as SECIS-binding protein (SBP2) and Sec-specific translation elongation factor (eEF$\mathrm{Sec})$, which all together allow for insertion of Sec instead of premature termination of biosynthesis (as UGA usually 
serves as the termination codon) $[1,2]$. The uniqueness of selenium is also reflected by its biological activity, in terms of which the element is most often described as "doubleedge sword," "essential poison," or "two-faced element" [3]. That is due to high redox properties-Se exerts both nutritional and toxic activities within a relatively narrow range of doses, highlighted by a relatively small difference between the recommended daily intake $(55 \mu \mathrm{g}$ or $70 \mu \mathrm{g}$ in USA and Europe, respectively) and the estimated upper tolerable limit $(300,400$, or $450 \mu \mathrm{g} / \mathrm{day}$ according to different sources) [4-6]. Most of the scientific interest related to $\mathrm{Se}$ is associated with its anticancer properties, which have been suggested based on numerous in vitro and in vivo studies as well as on some, although not all, human observational studies and human long-term supplementation trials $[7,8]$. Mechanism of anticancer activity of Se remains elusive, but it is generally considered that it results both from antioxidant- and redox-related properties of Se, exerted at a nutritional level and linked mainly to the activity of selenium-dependent enzymes (selenoproteins with catalytic activity), as well as from its prooxidant effects, observed at supranutritional intake and associated with the activity of low molecular weight Se compounds [9-12]. However, in the recent years, the hypothesis on cancer protective activity of Se has been seriously undermined by the results of a large, randomized double-blind prospective study, i.e., SELECT, which has been conducted to test whether Se (as selenomethionine) and vitamin E (as alpha-tocopherol) may reduce the risk of prostate cancer in men, and which has finally failed to indicate any protective effects of the element, either alone or in the combination with vitamin E [13]. Additionally, some concern has been paid to Se supplementation in terms of its possible diabetogenic effects, adding more uncertainty to assessing the relationship between selenium and human health $[14,15]$.

On the basis of several gene association studies, pointing to the importance of genetic polymorphism in the risk of human cancer as well as other diseases, it has been hypothesized that biological activity of Se in the human body may be modified by genetic polymorphism of selected selenoproteins $[16,17]$. Human selenoproteins cover many biologically important functions like those related to antioxidant defense system, thyroid hormone metabolism, and redox balance maintenance, all of which are driven mainly by redox-related selenoproteins, including five glutathione peroxidases (GPx1, GPx2, GPx3, GPx4, GPx6), three iodothyronine deiodinases (DI1, DI2, DI3), three thioredoxin reductases (TRxR1, TRxR2, TRxR3), or methionine-Rsulfoxide reductase (MsrB1, known also as SelR or SelX). Selenoprotein P (Sepp1) is the only selenoprotein which possesses multiple $\mathrm{Sec}$ residues and which is mainly responsible for Se transport within the body, but has been also shown to exert catalytic and antioxidant activities [18].
Functions of other selenoproteins are specifically linked to the selenoprotein synthesis (selenophoshate synthetase 2-SPS2), muscle development (selenoprotein N-SelN) or endoplasmic reticulum function (15-kDa selenoprotein-Sep15, selenoprotein S-SelS, selenoprotein $\mathrm{K}$ SelK), whereas functions of many other (like selenoprotein $\mathrm{H}-\mathrm{SelH}$, selenoprotein I-SelI, selenoprotein M-SelM, selenoprotein $\mathrm{O}-\mathrm{SelO}$, selenoprotein $\mathrm{W}-\mathrm{SelW}$, selenoprotein $\mathrm{T}$-SelT, or selenoprotein $\mathrm{V}-\mathrm{SelV}$ ) still remain unknown $[19,20]$. It has been demonstrated that some polymorphic variants in genes encoding for selected selenoproteins, including GPXI (glutathione peroxidase 1), GPX4 (glutathione peroxidase 4), SEPP1 (selenoprotein P), SELS (selenoprotein S), and SEP15 (15-kDa selenoprotein), have functional significance and may influence expression or activity of the protein either at the transcription, translation, or posttranslational level, thus explaining their association with the altered risk of cancer at several sites [17].

Despite the commonly appreciated approach to include genetic profile in the design of intervention trials or in the interpretation of study results, only few authors have followed this direction, and those who have, focused only on single, specific end points linked mainly to oxidative stress markers and/or DNA damage [21-25]. Notably, the genotype modifying effects are more likely to be observed within the subjects with a relatively low Se status [24]. Thus, the aim of this study was to analyze the potential influence of two functional single-nucleotide polymorphisms (SNPs), present within the coding region of two selenoprotein genes: GPX1 rs1050450 (Pro198Leu) and SEPP1 rs3877899 (Ala234Thr), on the multilevel biological response to Se supplementation. Due to a low dietary intake of Se in the Polish population [26], individuals from Poland who constituted the study group seemed to be relevant to investigate the possible gene-selenium interactions. Biomarkers of relevance included markers of $\mathrm{Se}$ status (plasma Se and Sepp1 concentrations), markers of oxidative stress (activity of antioxidant enzymes in plasma or erythrocytes, plasma lipid peroxidation, oxidative burst in the whole-blood leukocytes), DNA strand breaks, DNA oxidation, and mRNA expression of selected encoding selenoproteins or related genes (GPXI, GPX4, TRXR1, SEP15, SEPP1, SELS, SELW, SBP2).

\section{Methods}

\section{Study design}

By means of advertisement in different public places, 517 residents of Lodz in the age 18-60 were recruited for the study. Questionnaire data and $4 \mathrm{~mL}$ of fasting blood were collected from the subjects, followed by DNA isolation and 
Table 1 Baseline characteristics of the study group

\begin{tabular}{|c|c|c|}
\hline Characteristics & $N(\%)$ & Mean \pm SD (range) \\
\hline All & $95(100)$ & \\
\hline Males & $43(45)$ & \\
\hline Females & $52(55)$ & \\
\hline Age (years) & $95(100)$ & $35.6 \pm 10.8(18-60)$ \\
\hline$<30$ & $31(32.6)$ & \\
\hline $31-40$ & $41(43.2)$ & \\
\hline $41-50$ & $9(9.5)$ & \\
\hline $51-60$ & $14(14.7)$ & \\
\hline $\mathrm{BMI}\left(\mathrm{kg} / \mathrm{m}^{2}\right)$ & $95(100)$ & $23.8 \pm 3.1(17.9-34.9)$ \\
\hline$<25$ & $68(71.6)$ & \\
\hline $25-30$ & $23(24.2)$ & \\
\hline$>30$ & $4(4.2)$ & \\
\hline \multicolumn{3}{|l|}{ Smoking } \\
\hline Current & $0(0)$ & \\
\hline Ever & $25(26.3)$ & \\
\hline In the past 5 years & $10(9.5)$ & \\
\hline Never & $70(73.7)$ & \\
\hline \multicolumn{3}{|l|}{ Passive smoking } \\
\hline Yes & $25(26.3)$ & \\
\hline No & $70(73.7)$ & \\
\hline \multicolumn{3}{|l|}{ Alcohol consumption } \\
\hline Never & $5(5.3)$ & \\
\hline Less than 1 day per month & $30(31.6)$ & \\
\hline Less than 1 day per week & $34(35.8)$ & \\
\hline Up to 2 days per week & $25(26.3)$ & \\
\hline $3-5$ days per week or more & $1(1.1)$ & \\
\hline \multicolumn{3}{|c|}{ Vitamin or mineral supplements use } \\
\hline Yes, sporadically & $34(35.8)$ & \\
\hline Yes, regularly & $23(24.2)$ & \\
\hline No & $38(40.0)$ & \\
\hline \multicolumn{3}{|c|}{ Selenium containing supplements use in the past 6 months } \\
\hline Yes & $5(5.3)$ & \\
\hline No & $90(94.7)$ & \\
\hline
\end{tabular}

prospective genotyping for GPXI rs1050450 and SEPPI rs3877899. In a whole group of 517 recruited subjects, GPX1 allelic variants were in Hardy-Weinberg equilibrium ( $p=0.582$ ), and the genotype distribution was as follows: 46, 43, and $11 \%$ for ProPro, ProLeu, and LeuLeu, respectively. SEPP1 genotype frequencies were 60, 32, and $7.5 \%$ for AlaAla, AlaThr, and ThrThr, respectively, with a slight deviation from Hardy-Weinberg equilibrium ( $p=0.013$ ). The exclusion criteria for the supplementation trial included current smoking, chronic diseases such as cancer, diabetes, or cardiovascular disease, BMI higher than 35 as well as incomplete data for genetic analyses. Altogether 137 subjects were excluded. Further selection of the remaining 380 volunteers was based on the approximate major and minor allele distribution in order to obtain an as high as possible number of individuals with rare genotypes (GPX1 Leu/Leu and SEPP1 Thr/Thr) and to increase statistical power of comparison tests. Namely, all the subjects with rare genotypes were asked to participate in the supplementation trial, whereas subjects with common alleles were matched for age and BMI. Altogether 95 subjects agreed to participate in the trial. The study group characteristics are presented in Table 1. Genotype distribution is shown in Table 2, whereas Figure S1 presents the numbers of subjects with different genotype combinations. The selected 95 subjects, including 43 men and 52 women at the mean age of 35.6 years, were receiving $200 \mu \mathrm{g}$ of selenium in a form of selenium yeast for 6 weeks. Se yeast tablets were obtained commercially, and all were from the same batch. During the supplementation trial, as well as during the washout period, the participants were asked not to take any supplements containing vitamins and selenium or other elements. Fasting blood was collected during the study at four time points: before the supplementation assigned as baseline (the first day of the trial, before taking the first tablet), after 2 and 6 weeks of supplementation, and after 4 weeks of the washout period. Blood samples were collected from each participant in two heparin tubes

Table 2 Genotype distribution for GPX1 rs1050450 and SEPP1 rs3877899 polymorphisms and baseline characteristics according to genotype

\begin{tabular}{|c|c|c|c|c|c|c|}
\hline Genotype & $N(\%)$ & $\begin{array}{l}\text { Age, years (median } \\
\text { and range) }\end{array}$ & Sex (females/males) & $\begin{array}{l}\text { BMI (median and } \\
\text { range) }\end{array}$ & $\begin{array}{l}\text { Plasma Se, } \mu \mathrm{g} / \mathrm{L} \\
\text { (median and range) }\end{array}$ & $\begin{array}{l}\text { Plasma Sepp } 1 \mathrm{ng} / \mathrm{mL} \\
\text { (median and range) * }\end{array}$ \\
\hline \multicolumn{7}{|c|}{$G P X 1$ rs 1050450} \\
\hline Pro/Pro & $39(41 \%)$ & $33.0(18.0-60.0)$ & $1.29(22 / 17)$ & $22.9(18.0-33.1)$ & $63.3(34.3-109.1)$ & $3.9(0.9-26.4)$ \\
\hline Pro/Leu & $35(37 \%)$ & $37.0(18.0-58.0)$ & $1.06(18 / 17)$ & $23.7(17.9-31.1)$ & $62.7(35.8-103.2)$ & $4.2(1.3-36.0)$ \\
\hline Leu/Leu & $21(22 \%)$ & $34.0(18.0-58.0)$ & $1.33(12 / 9)$ & $24.6(20.1-34.9)$ & $62.5(37.2-96.2)$ & $3.6(1.0-6.4)$ \\
\hline \multicolumn{7}{|c|}{ SEPP1 rs3877899 } \\
\hline Ala/Ala & $46(48 \%)$ & $33.0(20.0-58.0)$ & $0.92(22 / 24)$ & $23.4(18.7-31.1)$ & $66.3(37.2-106.1)^{\mathrm{a}}$ & $3.1(1.0-26.9)$ \\
\hline Ala/Thr & $29(31 \%)$ & $33.0(18.0-58.0)$ & $1.90(19 / 10)$ & $22.9(17.9-27.7)$ & $68.9(34.3-96.2)^{\mathrm{a}}$ & $4.2(0.9-36.0)$ \\
\hline $\mathrm{Thr} / \mathrm{Thr}$ & $20(21 \%)$ & $36.5(18.0-60.0)$ & $1.22(11 / 9)$ & $23.7(18.9-34.9)$ & $52.0(35.8-109.1)^{\mathrm{a}}$ & $4.3(1.1-23.4)$ \\
\hline
\end{tabular}

* Skewed data; for these parameters, $p$ values (one-way ANOVA) were calculated for log-transformed data

${ }^{\mathrm{a}} p$ for linear trend $=0.04$ 
and two EDTA tubes. The material collected in the first heparinized tube $(7.5 \mathrm{~mL})$ was fractioned by centrifugation into plasma, buffy coat, and erythrocytes and frozen at $-20{ }^{\circ} \mathrm{C}$ until biochemical analyses. Whole blood $(4.5 \mathrm{~mL})$ from the second heparin tube was used for oxidative burst assessment, which was performed at the day of blood collection (this analysis was performed only at two time points: at baseline and after 2 weeks of supplementation). EDTA whole blood $(1.5 \mathrm{~mL})$ was used for leukocyte lysate preparation, which was subsequently stored at $-70{ }^{\circ} \mathrm{C}$ until mRNA isolation (for gene expression analysis). Whole blood $(2.7 \mathrm{~mL})$ from the second EDTA tube was used to prepare agarose slides for the comet assay (this analysis was performed at three time points: at baseline, after 6 weeks of supplementation, and after 4 weeks of the washout period). Along with the blood collection, detailed questionnaire data were collected each time, concerning current health status (well-being with respect to adverse health effects), intake of medications, dietary supplements, herbs or pharmacological treatment with hormones, antibiotics, statins, and other. All the analyses, apart from the oxidative burst assessment, were conducted after completing the study, and all the samples were blinded in terms of genotype and the time point of their collection. All the study participants gave written informed consent, and the subjects who were enrolled for the supplementation trial received detailed, written, and oral information about the trial. The study was approved by the Local Ethics Committee (Ethical Institutional Review Board at the Nofer Institute of Occupational Medicine, Lodz, Poland).

\section{DNA isolation and SNP genotyping}

DNA was isolated from buffy coat, using QIAamp DNA Blood Mini Kit (Qiagen, Hilden, Germany). Allelic discrimination for the two studied polymorphisms was performed using the real-time PCR method and CFX96 ${ }^{\mathrm{TM}}$ Real-Time PCR Detection System (Bio-Rad, Hercules, CA, USA). GPX1 rs1050450 genotyping was conducted using the high-resolution melt curve (HRM) technique. Oligonucleotide sequences for PCR primers, designed by Beacon Designer ${ }^{\mathrm{TM}}$ (PREMIER Biosoft, Palo Alto, CA, USA), were as follows: $5^{\prime}$-GCCGCTTCCAGACCATTG-3' (forward) and 5'-GGTGTTCCTCCCTCGTAG-3' (reverse). Data analysis was performed using Bio-Rad CFX Manager and Bio-Rad Precision Melt Analysis Software. Identification of particular genotypes recognized by HRM was based on the comparison with the method introducing specific fluorescent probes, as described previously [27]. For SEPP1 rs3877899 analysis, the TaqMan ${ }^{\circledR}$ SNP Genotyping Assay (C_8709053_10, Life Technologies, Life Technologies, Carlsbad, CA, USA) was used. The call rate for two SNPs was $>99 \%$, and the concordance of the blinded QC $(n=12)$ was $100 \%$.
mRNA isolation, cDNA synthesis, and gene expression

WBC lysates and mRNA isolation were performed using the QIAamp RNA Blood Mini Kit (Qiagen, Hilden, Germany), and reverse transcription was performed using the QuantiTect Kit (Qiagen, Hilden, Germany). Both cDNA synthesis and real-time PCR were conducted in the Light Cycler 96 Real-Time PCR System (Roche, Indianapolis, IN, USA). cDNA was stored at $-20{ }^{\circ} \mathrm{C}$ until gene expression experiments. Primers' sequences and amplicons' sizes are presented in Table S1. Real-time PCRs were carried out in three replications for each sample. $20 \mu \mathrm{L}$ reaction mixture contained $1 \mu \mathrm{L}$ of cDNA, $10 \mu \mathrm{L}$ of $2 x$ FastStart SYBR Green Master (Roche, Indianapolis, IN, USA), 20 pmol of each primer, and nuclease-free water (Qiagen, Hilden, Germany). PCR conditions were as follows: polymerase activation at $95{ }^{\circ} \mathrm{C}$ for $10 \mathrm{~s}$, followed by 45 cycles: denaturation at $95{ }^{\circ} \mathrm{C}$ for $15 \mathrm{~s}$, annealing at $60^{\circ} \mathrm{C}$ for $45 \mathrm{~s}$, and polymerization at $72{ }^{\circ} \mathrm{C}$ for $45 \mathrm{~s}$. Inter- and intra-assay variations, as determined by three occasional, intra-experimental runs of five cDNA triplicates, were below 12 and $10 \%$, respectively. PCR efficiencies were calculated using five dilutions of pooled cDNA, consisting of randomly selected samples. As confirmed by the initial data analysis, expression of the reference gene $(G A P D H)$ was stable under experimental conditions. Normalized relative quantification of the target genes' expression was evaluated including reaction efficiency correction, by the use of the qbasePLUS software, version: 2.3) (Biogazelle NV, Zwijnaarde, Belgium).

\section{Plasma selenium concentration}

Plasma sample used for determination of selenium concentration was initially diluted with Triton X-100 (0.2 \%, Sigma-Aldrich, St. Louis, MO, USA) in a proportion 1:1. Concentration was assessed using Zeeman flameless atomic absorption spectrometry (instrument Z-5000, Hitachi) with graphite tube and palladium/magnesium matrix modifier (Pd-1500 ppm, Mg-900 ppm). The limit of detection was $1.4 \mu \mathrm{g} / \mathrm{L}$. The certified reference material Seronorm Trace Elements Serum (SERO AS, Billingstad, Norway) was used for the quality control assessment. The accuracy of the method and coefficient of variance $(\mathrm{CV})$ were 1.3 and $4.7 \%$, respectively.

\section{Plasma selenoprotein $\mathbf{P}$ concentration}

Sepp1 concentration was determined in plasma using the immunochemical Sandwich ELISA test (USCN Life Science Inc kit, $\mathrm{Hu}$, China). In brief, plasma samples were diluted 500-1000 times and added to the plate wells with biotin-conjugated polyclonal antibody specific for Sepp1. Next, avidin-conjugated horseradish peroxidase was added, 
and after incubation with TMB (3,3',5,5'-tetramethylbenzidine), the substrate solution color change was observed proportionally to Sepp1 concentration. The reaction was terminated with sulfuric acid solution, and color intensity was measured at a wavelength of $450 \mathrm{~nm}$. For each test, a standard curve was determined (range $0.78-50 \mathrm{ng} / \mathrm{mL}$ ), and Sepp1 concentration was calculated after plotting logarithmic curve. Intra-assay and inter-assay variations were 8.0 and $12.7 \%$, respectively.

\section{Activity of antioxidant enzymes}

Spectrophotometric methods were used to analyze blood compartments for the activity of GPx1, GPx3, SOD1, and $\mathrm{Cp}$. The activity of glutathione peroxidases was determined in erythrocytes (GPx1) and plasma (GPx3) using the method of Paglia and Valentine [28] with t-butyl hydroperoxide as a substrate and following the rate of NADPH oxidation by the coupled reaction with glutathione reductase. The rate of decrease in the absorbance, being proportional to the GPx activity, was read at a wavelength of $340 \mathrm{~nm}$. The activity of SOD1 was determined in erythrocytes by the use of the method of Beauchamp and Fridovich [29], which relies on the inhibition by SOD1 of the reduction of nitro blue tetrazolium (NBT) by xanthine and xanthine oxidase. The concentration of the reduced form of NBT was measured at a wavelength of $540 \mathrm{~nm}$. The oxidase activity of Cp was determined in plasma according to the method described by Sunderman and Nomoto [30], with a PPD ( $p$-phenylenediamine) as a substrate. The absorbance of the oxidation product was read at a wavelength of $535 \mathrm{~nm}$. The activity of $\mathrm{Cp}$ was expressed as the amount of product formed per minute per $1 \mathrm{~L}$ of plasma. All the absorbance values were read using the Unicam UV4 UV/Vis spectrophotometer (Cambridge, UK).

\section{Total antioxidant capacity}

The total antioxidant capacity of plasma was determined calorimetrically by the use of the Antioxidant Assay Kit (Cayman Chemical Company, Ann Arbor, MI, USA). Absorbance measurement was taken on a spectrophotometer MultiScan GO (Thermo Scientific, Waltham, MA, USA).

\section{Lipid peroxidation}

Plasma concentration of thiobarbituric acid-reactive substances (TBARS) was determined using the spectrofluorometric method, optimized by Wasowicz et al. [31]. TBAreactive compounds were extracted to butanol. The value of fluorescence of butanol layer was read at an excitation wavelength of $525 \mathrm{~nm}$ and an emission wavelength of
$547 \mathrm{~nm}$, using the PerkinElmer Luminescence Spectrometer LS50B (Norwalk, Ct, USA).

\section{Oxidative burst}

Oxidative burst (generation of reactive oxygen species, ROS) was measured using flow cytometry and fluorescent labeling with $2^{\prime}, 7^{\prime}$-dichlorodihydrofluorescein diacetate ( DCFH $_{2}$-DA, Sigma-Aldrich, St. Louis, MO, USA). The fluorescence was read in the FACSCanto II flow cytometer (BD Biosciences, San Jose, CA, USA) and expressed as the mean fluorescent intensity (MFI). The final results were expressed as the MFI ratio, calculated as the ratio of PMA stimulated cells MFI to MFI of basal ROS production. In each sample, at least 20,000 cells were examined.

\section{DNA damage}

DNA damage, including the strand breaks (SB) and alkalilabile sites (ALS), was assayed in whole blood using alkaline single-cell gel electrophoresis (SCGE; comet assay) method as described by Singh et al. [32] and modified by Mc Kelvey-Martin et al. [33]. One aliquot of whole blood was mixed with nine aliquots of RPMI-1640 medium and 10 aliquots of $2 \%$ (in PBS) molten agarose type VII (low gelling temperature). The mixture was then spread on a slide earlier covered with agarose type I (low EEO) at $1 \%$ concentration in water and dried. The cells embedded in the agarose gel were lysed in cold lysing solution $(2.5 \mathrm{M} \mathrm{NaCl}$, $100 \mathrm{mM}$ Na2EDTA, $10 \mathrm{mM}$ Tris base, pH 10, with $1 \%$ Triton X-100 added just before use) at $4{ }^{\circ} \mathrm{C}$ for $1 \mathrm{~h}$. Subsequently, DNA was unwound in an alkaline electrophoresis buffer (1 mM Na2EDTA, $300 \mathrm{mM} \mathrm{NaOH}, \mathrm{pH} 13)$ for $20 \mathrm{~min}$ and electrophoresed in the same alkaline conditions ( $30 \mathrm{~min}, 25 \mathrm{~V}, 300 \mathrm{~mA}, 1.04 \mathrm{~V} / \mathrm{cm}$ ). The gels were then neutralized by rinsing three times with $0.4 \mathrm{M}$ Tris buffer ( $\mathrm{pH}$ 7.5), and the slides were dried for storage. In parallel analyses, oxidatively generated damage to DNA bases was additionally identified as formamidopyrimidine glycosylase (FPG)-sensitive sites using modified comet assay as described earlier by Collins et al. [34]. FPG enzyme was purchased from New England Biolabs (Hithchin, UK). After lysis, the slides were washed three times with an enzyme buffer $(0.1 \mathrm{M} \mathrm{KCl}, 0.5 \mathrm{mM}$ Na2EDTA, $40 \mathrm{mM}$ HEPES-KOH, $0.2 \mathrm{mg} / \mathrm{ml}$ bovine serum albumin, $\mathrm{pH} 8$ ) and incubated with FPG at $2.7 \mathrm{U} / \mathrm{mL}$ in this buffer (kept at $-80{ }^{\circ} \mathrm{C}$ ) for $30 \mathrm{~min}$ at $37{ }^{\circ} \mathrm{C}$. The slides were then electrophoresed and neutralized as described above. Finally, the slides were stained with $5 \mu \mathrm{g} / \mathrm{mL}$ DAPI, and 50 cells from each slide were analyzed using an Olympus fluorescence microscope (a BX40 instrument; Olympus, Tokyo, Japan) equipped with an image analysis system (Comet IV, Perceptive Instruments, UK). For each participant, four slides 
were prepared simultaneously: two for assessment of DNA strand breakage and the other two, which included also the FPG treatment, for the assessment of total DNA damage (i.e., DNA strand breakage and oxidatively generated DNA damage). Respective DNA damage was inferred based on the relative amount of DNA in the comet tail (henceforth referred to as \% tail DNA) obtained via computer-aided image analysis. DNA oxidation damage was expressed as the difference between the total DNA damage and DNA strand breaks, i.e., "net FPG-sensitive sites."

\section{Statistical analysis}

Data normality was assessed using Shapiro-Wilk test. In the case of abnormal distributions, an analysis was performed on the log-transformed values. Baseline differences between males and females were assessed by the use of the $t$ test, while correlations among baseline parameters and individuals' characteristics were evaluated by the Pearson correlation coefficient. Differences in the distribution of baseline parameters (age, BMI, baseline selenium, and plasma Sepp1 concentration) according to GPX1 rs1050450 and SEPP1 rs3877899 genotypes were evaluated by one-way ANOVA. Repeated measures analysis of covariance (ANCOVA, MANCOVA) was carried out to test the effects of particular genotype or genotypes interaction on the studied biological parameters. With MANCOVA analysis, parameters measured at different time points were considered as dependent variables, while genotypes and covariates were included in the models as independent variables. Covariates included age, sex, BMI, and baseline selenium. The effect of Se supplementation (time effect/ within subjects effect) as well as the effect of interaction between genotype and Se supplementation was assessed using MANCOVA test methods (Wilk's lambda statistics) with the unstructured covariance matrix. Post hoc comparisons between pairwise time points were performed by contrast tests. All the assays were performed at a significance level of $\alpha=0.05$. In order to take into account the problem of multiple comparisons, along with original $p$ values, the false discovery rate (FDR), adjusted $p$ values were also calculated and reported in the text, where appropriate. Statistical analyses were conducted using SAS software, version 9.2 (SAS Institute, Cary, NC, USA).

\section{Results}

\section{Course of the study}

All the individuals completed the supplementation trial. There was also $100 \%$ responsiveness to the questionnaires introduced at each time point of blood collection, and all the subjects reported to take Se yeast tablets regularly ( 1 tablet/day) for 6 weeks. Nobody declared smoking tobacco and taking Se containing supplements during the study. Dietary questionnaires concerned frequency of consumption of food products which contain the highest Se content in the Polish diet (according to our previous study [26]). As shown in supplementary figures (Figure S2), the overall consumption frequency of eggs, fish, and nuts was similar during 6-week period of supplementation as compared to the washout. Additionally, we collected data on factors (consumption of drugs, hormones, dietary supplements etc.) that could potentially affect results of the study (Table S2). Subjective side effects observed during supplementation, as reported by two female participants included short nausea directly after taking the supplement (one female) and vaginal thrush (the other female).

\section{Sex and genotype differences at baseline}

Significant differences between males and females at baseline were observed for BMI (24.9 vs. 22.8, respectively, $p<0.0001)$ and GPx1 activity (16.1 vs. $18.2 \mathrm{U} / \mathrm{g} \mathrm{Hb}$, $p=0.01)$. Significant positive correlations with age were found in females for BMI $(\rho=0.34, p=0.01)$, plasma Se or Sepp 1 concentrations $(\rho=0.51, p=0.0001 ; \rho=0.39$, $p=0.02$, respectively), and TBARS ( $\rho=0.43, p=0.002$ ). In males, positive significant correlations with age were observed only for TBARS ( $\rho=0.54, p=0.0002)$.

Numbers of male and female subjects within each genotype subgroup were similar (Table 2). There were no significant differences at baseline in terms of age, BMI, and Se status between the subjects with different $G P X I$ genotype. SEPP1 polymorphism was shown to significantly affect the baseline plasma Se concentration (in a linear manner), whereas no baseline differences were observed in terms of age, BMI, and plasma Sepp1 concentration.

\section{Se supplementation effects}

Table 3 presents median values and a range of markers for selenium status (plasma concentrations of Se and Sepp1), oxidative stress (the activities of GPx1, GPx3, SOD1 and Cp, TAC, TBARS, and ROS generation), and DNA damage (at the level of DNA strand breaks and DNA oxidation) measured at baseline, during the supplementation trial and after 4 weeks of the washout period. Both plasma Se and Sepp1 median concentrations were significantly increased after 2 weeks of supplementation $(98.00 \mu \mathrm{g} / \mathrm{L}$ vs. $62.65 \mu \mathrm{g} / \mathrm{L}$ and 7.36 vs. $3.86 \mathrm{ng} / \mathrm{mL}$, respectively; $p<0.0001$ and $p<0.0001$, respectively) and after 6 weeks of supplementation $(93.84 \mu \mathrm{g} / \mathrm{L}$ and $6.14 \mathrm{ng} /$ $\mathrm{mL}$, respectively; $p<0.0001$ and $p<0.0001$ vs. baseline, 
Table 3 Effect of Se supplementation on the studied biological parameters, including markers of selenium status, oxidative stress and DNA damage. Data presented regardless of genotype

\begin{tabular}{|c|c|c|c|c|c|}
\hline \multirow[t]{2}{*}{ Marker } & \multicolumn{4}{|c|}{ Median and range, measured at four different time points } & \multirow[t]{2}{*}{$p$ value (MANCOVA) $* *$} \\
\hline & Baseline & 2 weeks & 6 weeks & Washout & \\
\hline $\mathrm{Se}(\mu \mathrm{g} / \mathrm{L})$ & $\begin{array}{l}62.65^{\mathrm{a}} \\
(34.32-109.12)\end{array}$ & $\begin{array}{l}98.00^{\mathrm{b}} \\
(56.49-183.86)\end{array}$ & $\begin{array}{l}93.84^{\mathrm{b}} \\
(54.92-148.76)\end{array}$ & $\begin{array}{l}74.61^{\mathrm{c}} \\
(49.27-111.58)\end{array}$ & $p<\mathbf{0 . 0 0 0 1}$ \\
\hline Sepp1 $*(\mathrm{ng} / \mathrm{mL})$ & $\begin{array}{l}3.86^{\mathrm{a}} \\
(0.86-36.03)\end{array}$ & $\begin{array}{l}7.36^{\mathrm{b}} \\
(0.97-41.60)\end{array}$ & $\begin{array}{l}6.14^{\mathrm{c}} \\
(0.26-34.08)\end{array}$ & $\begin{array}{l}6.00^{\mathrm{c}} \\
(0.66-31.20)\end{array}$ & $p<0.0001$ \\
\hline GPx1 (U/gHb) & $\begin{array}{l}17.10^{\mathrm{a}} \\
(9.68-29.04)\end{array}$ & $\begin{array}{l}16.24^{\mathrm{a}} \\
(8.93-28.17)\end{array}$ & $\begin{array}{l}24.43^{\mathrm{b}} \\
(11.95-29.88)\end{array}$ & $\begin{array}{l}23.76^{\mathrm{b}} \\
(14.03-29.96)\end{array}$ & $p<0.0001$ \\
\hline GPx3 (U/mL) & $\begin{array}{l}0.18^{\mathrm{a}} \\
(0.12-0.25)\end{array}$ & $\begin{array}{l}0.18^{\mathrm{a}} \\
(0.12-0.26)\end{array}$ & $\begin{array}{l}0.20^{\mathrm{b}} \\
(0.14-0.28)\end{array}$ & $\begin{array}{l}0.19^{\mathrm{c}} \\
(0.12-0.26)\end{array}$ & $p<0.0001$ \\
\hline SOD1 (U/mg Hb) & $\begin{array}{l}6.20 \\
(3.93-8.39)\end{array}$ & $\begin{array}{l}6.12 \\
(3.04-9.38)\end{array}$ & $\begin{array}{l}6.02 \\
(4.34-8.50)\end{array}$ & $\begin{array}{l}6.00 \\
(3.93-8.75)\end{array}$ & $p=0.21$ \\
\hline $\mathrm{Cp}(\mathrm{g} / \mathrm{L})$ & $\begin{array}{l}0.46^{\mathrm{a}} \\
(0.24-0.91)\end{array}$ & $\begin{array}{l}0.49^{\mathrm{b}} \\
(0.30-0.87)\end{array}$ & $\begin{array}{l}0.48^{\mathrm{b}} \\
(0.34-0.79)\end{array}$ & $\begin{array}{l}0.49^{\mathrm{b}} \\
(0.34-0.78)\end{array}$ & $p=\mathbf{0 . 0 1}$ \\
\hline $\mathrm{TAC} *(\mathrm{mmol} / \mathrm{L})$ & $\begin{array}{l}0.85^{\mathrm{a}} \\
(0.03-5.08)\end{array}$ & $\begin{array}{l}1.18^{\mathrm{b}} \\
(0.10-4.99)\end{array}$ & $\begin{array}{l}1.36^{\mathrm{c}} \\
(0.05-5.25)\end{array}$ & $\begin{array}{l}2.02^{\mathrm{d}} \\
(0.24-5.95)\end{array}$ & $p<0.0001$ \\
\hline TBARS $*(\mathrm{mmol} / \mathrm{mL})$ & $\begin{array}{l}1.75^{\mathrm{a}} \\
(1.00-4.08)\end{array}$ & $\begin{array}{l}1.98^{\mathrm{b}} \\
(1.02-4.24)\end{array}$ & $\begin{array}{l}2.02^{\mathrm{b}} \\
(1.02-4.52)\end{array}$ & $\begin{array}{l}2.08^{\mathrm{b}} \\
(1.01-3.29)\end{array}$ & $p<0.0001$ \\
\hline RFT (MFI index) & $\begin{array}{l}78.90^{\mathrm{a}} \\
(22.35 \pm 134.12)\end{array}$ & $\begin{array}{l}\mathbf{6 7 . 6 6}^{\mathrm{b}} \\
(32.18 \pm 113.57)\end{array}$ & na & na & $p<0.0001$ \\
\hline DNA strand breaks ( $\%$ tail DNA)* & $\begin{array}{l}1.86^{\mathrm{a}} \\
(0.57-5.50)\end{array}$ & na & $\begin{array}{l}1.91^{\mathrm{a}} \\
(0.63-3.90)\end{array}$ & $\begin{array}{l}2.10^{\mathrm{b}} \\
(1.02-6.08)\end{array}$ & $p<0.0001$ \\
\hline DNA oxidation ( $\%$ tail DNA) & $\begin{array}{l}2.58^{\mathrm{a}} \\
(0.00-5.74)\end{array}$ & na & $\begin{array}{l}2.35^{\mathrm{a}, \mathrm{b}} \\
(0.00-6.23)\end{array}$ & $\begin{array}{l}3.08^{\mathrm{c}} \\
(0.00-6.49)\end{array}$ & $p<0.0001$ \\
\hline
\end{tabular}

Statistically significant $p$ values (last column) and values significantly different as compared to baseline are typed in bold. Values indexed with different upper case letters $(\mathrm{a}, \mathrm{b}, \mathrm{c}, \mathrm{d})$ are significantly different at $p \leq 0.05$ (contrast test for different time points, adjusted for age, sex, BMI, and baseline plasma Se)

na parameter was not analyzed at this time point

* Skewed data; for these parameters, $p$ values were calculated for log-transformed data

** Model adjusted for age, sex, BMI, and baseline plasma Se

respectively). After 4 weeks of washout, Se started to decrease $(74.61 \mu \mathrm{g} / \mathrm{L}, p<0.0001$ vs. 6 weeks); however, it was still significantly higher as compared to the baseline $(p<0.0001)$, whereas Sepp1 was not statistically different as compared to the median value observed after 6 weeks of supplementation $(6.00 \mathrm{ng} / \mathrm{mL}, p=0.270)$. GPx 1 and GPx3 activities were significantly higher as compared to the baseline after 6 weeks of supplementation ( 24.43 vs. 17.10 $\mathrm{U} / \mathrm{gHb}$ and 0.20 vs. $0.18 \mathrm{U} / \mathrm{mL}$, respectively; $p<0.0001$ and $p<0.0001$, respectively), and both started to decrease slightly after 4 weeks of the washout period, though statistically significant difference as compared to the sixth week's value was observed only for GPx3 $(0.19 \mathrm{U} / \mathrm{mL}$, $p<0.0001)$. Total plasma antioxidant capacity as well as lipid peroxidation was significantly increased already after 2 weeks of supplementation $(p=0.02$ and $p=0.0002$ vs. baseline, respectively) and remained significantly higher as compared to the baseline after 6 weeks of supplementation ( $p<0.0001$ and $p<0.0001$, respectively) and after 4 weeks of the washout period $(p<0.0001$ and $p<0.0001$ vs. baseline, respectively). Plasma $\mathrm{Cp}$ activity was significantly increased after 6 weeks ( $p=0.003$ vs. baseline) and remained significantly higher as compared to the baseline after 4 weeks of washout $(p=0.01)$. SOD1 activity remained unaffected during the supplementation trial. The ability of whole-blood granulocytes to generate ROS upon PMA stimulation, measured only after 2 weeks of supplementation, was significantly decreased as compared to the baseline $(p<0.0001)$. A statistically significant increase in DNA damage, assessed at three time points, as compared to the baseline, was observed after 4 weeks of the washout period, both at the level of DNA strand breaks ( $p<0.0001$ vs. the baseline) and at the level of DNA oxidation $(p<0.0001$ vs. baseline).

Table 4 presents mean values of the normalized relative gene expression, analyzed at baseline, after 2 weeks of supplementation, after 6 weeks of supplementation, and after 4 weeks of the washout period. Five out of eight analyzed genes (GPX1, GPX4, SEP15, SELS, and SELW) were affected in a negative manner upon Se supplementation. 
Table 4 Selectively suppressive effect of selenium supplementation at the level of mRNA expression (relative expression, normalized to $G A P D H)$. Data presented regardless of genotype

\begin{tabular}{|c|c|c|c|c|c|}
\hline \multirow[t]{2}{*}{ Gene } & \multicolumn{4}{|c|}{ Mean and SD, measured at four different time points } & \multirow{2}{*}{$\begin{array}{l}p \text { value, } \\
\text { (MANCOVA) }\end{array}$} \\
\hline & Baseline & 2 weeks & 6 weeks & Washout & \\
\hline$G P X 1$ & $1.425 \pm 0.212^{\mathrm{a}}$ & $1.411 \pm 0.187^{\mathrm{a}}$ & $1.355 \pm 0.194^{b}$ & $1.292 \pm 0.208^{c}$ & $p<0.0001$ \\
\hline$G P X 4$ & $1.355 \pm 0.217^{\mathrm{a}}$ & $1.294 \pm \mathbf{0 . 1 8 9}^{\mathrm{b}}$ & $1.284 \pm \mathbf{0 . 1 9 3}^{\mathrm{b}}$ & $1.251 \pm 0.206^{c}$ & $p=\mathbf{0 . 0 0 2}$ \\
\hline$T R X R 1$ & $1.742 \pm 0.226$ & $1.721 \pm 0.197$ & $1.748 \pm 0.195$ & $1.736 \pm 0.208$ & $p=0.60$ \\
\hline SEPP1 & $1.555 \pm 0.292^{\mathrm{a}, \mathrm{c}}$ & $1.590 \pm 0.316^{\mathrm{a}, \mathrm{b}}$ & $1.620 \pm 0.284^{\mathrm{a}, \mathrm{b}}$ & $1.467 \pm 0.318^{\mathrm{a}, \mathrm{c}}$ & $p=\mathbf{0 . 0 0 1}$ \\
\hline SEP15 & $1.625 \pm 0.179^{\mathrm{a}}$ & $1.579 \pm 0.181^{b}$ & $1.526 \pm 0.165^{c}$ & $1.536 \pm \mathbf{0 . 2 2 3}^{\mathrm{c}}$ & $p<\mathbf{0 . 0 0 1}$ \\
\hline SELS & $2.039 \pm 0.274^{\mathrm{a}}$ & $1.977 \pm 0.245^{\mathrm{a}}$ & $1.916 \pm 0.217^{b}$ & $1.886 \pm 0.309^{b}$ & $p<\mathbf{0 . 0 0 0 1}$ \\
\hline$S E L W$ & $1.220 \pm 0.218^{\mathrm{a}}$ & $1.183 \pm 0.218^{\mathrm{a}, \mathrm{b}}$ & $1.115 \pm \mathbf{0 . 2 1 3}^{\mathrm{b}}$ & $1.125 \pm 0.250^{b}$ & $p=\mathbf{0 . 0 0 0 3}$ \\
\hline$S B P 2$ & $1.470 \pm 0.212$ & $1.476 \pm 0.183$ & $1.472 \pm 0.233$ & $1.493 \pm 0.210$ & $p=0.73$ \\
\hline
\end{tabular}

Statistically significant $p$ values and mean values significantly different as compared to baseline expression are typed in bold. Values indexed with different upper case letters (a, b, c, d) are significantly different at $p \leq 0.05$ (contrast test for different time points, adjusted for age, sex, BMI, and baseline plasma Se)

* Model adjusted for age, sex, BMI, and baseline plasma Se
Expression of mRNA for these genes was significantly decreased as compared to the baseline after 6 weeks of supplementation ( $p=0.0002$ for GPX1, $p=0.001$ for GPX4, $p<0.0001$ for SEP15, $p<0.001$ for SELS, and $p<0.0001$ for $S E L W$ ) and remained significantly decreased as compared to the baseline after 4 weeks of the washout period $(p<0.0001$ for $G P X 1, p=0.0001$ for $G P X 4, p<0.0001$ for $S E P 15, p<0.0001$ for $S E L S$, and $p<0.001$ for $S E L W$ ). For two genes (GPX4, SEP15), a significant decrease as compared to the baseline was observed already after 2 weeks of supplementation ( $p=0.006$ and $p=0.02$, respectively). SEPP1 expression was the only case in which the expression was increased upon Se supplementation. However, the increase was not statistically significant as compared to the baseline, and it was significantly decreased after 4 weeks of the washout period ( $p=0.001$ and $p=0.0002$ vs. 2 weeks and 6 weeks, respectively). Expression of the two genes, $T R X R 1$ and $S B P 2$, remained unaffected.

\section{SNP alone effects and the interaction with Se supplementation}

The effects of GPX1 rs1050450 and SEPP1 rs3877899 polymorphisms are presented in Table 5 and Table S3. The effects were analyzed regardless of time and with respect to time interaction to assess the possible modulatory SNP effects upon Se supplementation.

\section{Se status}

Plasma Se and Sepp1 concentrations were not associated with $G P X 1$ rs1050450 ( $p=0.94$ and $p=0.17$, respectively) or SEPP1 $\operatorname{rs} 3877899(p=0.08$ and $p=0.13$, respectively) nor with the combination of those two polymorphisms ( $p=0.36, p=0.84$, respectively, Table 5). No modulatory effects were also observed for any of the two SNPs on the dynamic changes in Se status markers in response to Se supplementation (as assessed by the tests for interaction with time).

\section{Oxidative stress and DNA damage}

Statistically significant effects of GPXI rs 1050450 on GPx 1 activity ( $p=0.04$, Table 5$)$ and DNA oxidation $(p=0.002$; Table 5) were observed regardless of time (at each time point). According to the contrast tests, GPXI LeuLeu homozygotes were shown to differ significantly as compared to ProPro homozygotes and ProLeu heterozygotes, having the lowest GPx1 activity (Fig. 1a) and, at the same time, the highest level of DNA oxidation (Fig. 3). Additional analysis of mean GPx1 activity change after 6 weeks of Se supplementation with respect to GPXI rs 1050450 genotype confirmed the significant impact of this SNP on enzyme activity response, showing that GPXI LeuLeu individuals were characterized by a significantly lower increase upon supplementation as compared to the individuals possessing ProPro genotype $(p=0.008$; Fig. 1b).

After inclusion of time effect (SNP and time interaction), GPXI rs 1050450 was observed to modulate the response to Se supplementation at the level of GPx3 activity ( $p=0.05$; Table 5 ; Fig. 2$)$. In the explorative analysis of particular time points, GPx3 response was shown to be affected by the genotype specifically after 6 weeks of supplementation and during washout, with significantly higher values as compared to the baseline observed for ProPro homozygotes $(p<0.0001$ and $p=0.002$ for 6 weeks and washout, respectively) and ProLeu heterozygotes $p=0.001$ and $p=0.02$ for 6 weeks and washout, respectively), whereas GPx3 activity in LeuLeu homozygotes was not affected $(p=0.21$ and $p=0.66$ for 6 weeks and washout, respectively). 
Table 5 Effects of GPX1 rs1050450 and SEPP1 rs3877899 polymorphisms on the markers of selenium status, oxidative stress and DNA damage, interaction with time

\begin{tabular}{|c|c|c|c|}
\hline \multirow[t]{2}{*}{ Parameter } & \multicolumn{3}{|c|}{$p$ value for genotype effect (ANCOVA)* and for time interaction (MANCOVA)* } \\
\hline & GPX1 rs1050450 & SEPP1 rs3877899 & $G P X 1$ rs1050450 × SEPP1 rs3877899 \\
\hline $\operatorname{Se}(\mu \mathrm{g} / \mathrm{L})$ & $p=0.94$ & $p=0.08$ & $p=0.36$ \\
\hline Sepp1** $(\mathrm{ng} / \mathrm{mL})$ & $p=0.17$ & $p=0.13$ & $p=0.84$ \\
\hline GPx1 (U/gHb) & $\begin{array}{l}p=\mathbf{0 . 0 4} \\
\text { (Fig. 1a) }\end{array}$ & $p=0.33$ & $p=0.59$ \\
\hline GPx3 (U/mL) & $\begin{array}{l}p=0.47 \\
\text { Interaction with time: } \\
p=\mathbf{0 . 0 5} \text { (Fig. 2) }\end{array}$ & $p=0.33$ & $p=0.48$ \\
\hline $\mathrm{SOD} 1(\mathrm{U} / \mathrm{mg} \mathrm{Hb})$ & $p=0.91^{\mathrm{a}}$ & $\begin{array}{l}p=0.76 \\
\text { Interaction with time: } \\
p=\mathbf{0 . 0 2} \text { (Fig. 3) }\end{array}$ & $p=0.64$ \\
\hline $\mathrm{Cp}(\mathrm{g} / \mathrm{L})$ & $p=0.20$ & $p=0.70$ & $p=0.33$ \\
\hline $\mathrm{TAC}^{* *}(\mathrm{mmol} / \mathrm{L})$ & $p=0.76$ & $p=0.37$ & $p=0.97$ \\
\hline TBARS** $(\mathrm{mmol} / \mathrm{mL})$ & $p=0.09$ & $p=0.15$ & $p=0.65$ \\
\hline RFT (MFI index) & $p=0.14$ & $p=0.95$ & $p=0.74$ \\
\hline DNA strand breaks ( $\%$ tail DNA) & $\begin{array}{l}p=0.49 \\
\text { Interaction with time: } \\
p=\mathbf{0 . 0 5} \\
\text { (Fig. 4) }\end{array}$ & $p=0.72$ & $p=0.47$ \\
\hline DNA oxidation ( $\%$ tail DNA) & $\begin{array}{l}p<\mathbf{0 . 0 0 0 1} \\
\text { (Fig. 5) }\end{array}$ & $p=0.62$ & $p=0.65$ \\
\hline
\end{tabular}

Statistically significant $p$ values are typed in bold and supplied with graphical explanation on the indicated figure. For the interaction with time, only statistically significant $p$ values are presented. Statistically nonsignificant effects are shown in the supplementary Figures S3a-q

* Models adjusted for age, sex, BMI, and baseline plasma Se

** Skewed data; for these parameters, $p$ values were calculated for log-transformed data

Statistically significant SNP and time interaction was shown for GPX1 rs 1050450 also at the level of DNA strand breaks ( $p=0.05$; Table 5; Fig. 4). According to the analysis of particular time points, a significant increase in DNA damage, as compared to the baseline, was shown at washout and only for ProPro homozygotes $(p<0.0001)$.

Significant SEPP1 rs3877899 effect was limited only to the response of SOD1 activity upon Se supplementation ( $p=0.02$ for SNP and time interaction, Table 5; Fig. 5). According to the analysis of particular time points, a significant SOD1 decrease, as compared to the baseline, was observed specifically for AlaAla homozygotes during washout $(p=0.04)$.

\section{mRNA expression}

GPX1 rs1050450 and SEPP1 rs3877899 SNPs were not associated with any changes in the expression of related (encoded) genes. GPX1 rs1050450 was shown to modulate the expression of unrelated target, SEP15, upon Se supplementation, both alone $(p=0.03)$ and in combination with SEPP1 rs3877899 ( $p=0.04$; Table S3).

\section{False discovery rate analysis}

After FDR correction of $p$ values, significant effects were maintained for all the analyzed data regardless of the genotype (Tables 3,4), whereas most of the effects analyzed after genotype stratification were no more statistically significant (data not shown). The only genotype modulatory effect that remained statistically significant after FDR correction was the effect of GPX1 rs 1050450 polymorphism on DNA oxidation, regardless of time (FDR $p$ values: 0.02 ).

\section{Discussion}

\section{Final evidence that GPX1 Leu variant at rs1050450 is associated with a lower GPx1 response to Se}

This supplementation trial, conducted among 95 non-smoking individuals, prospectively genotyped for two redox active selenoproteins, confirmed the previously observed effect of GPX1 rs1050450 on GPx1 activity response to Se supplementation $[24,35]$. Glutathione peroxidase is an 

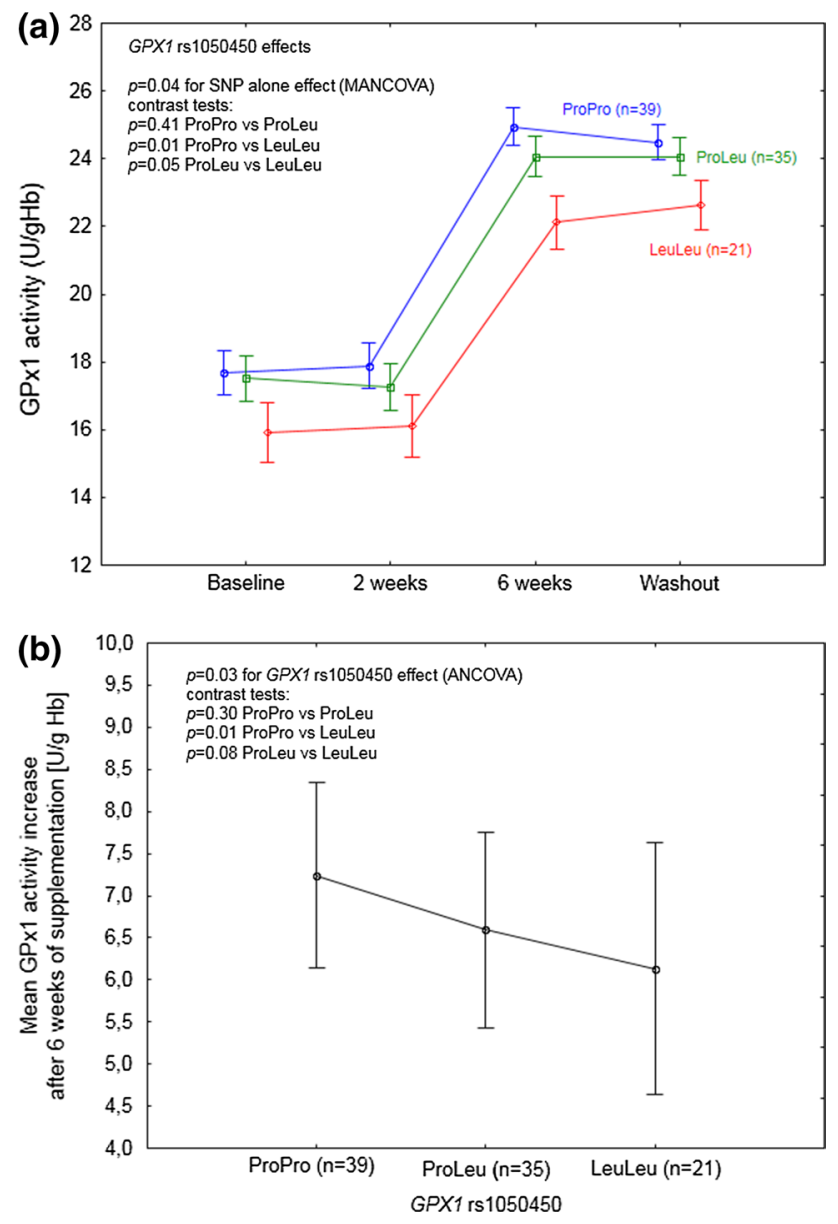

Fig. 1 a GPX1 rs1050450 effect on GPx1 activity in the individuals supplemented with selenium. A significant SNP effect was observed regardless of time. Data adjusted for age, sex, BMI, and baseline selenium; b mean GPx1 activity increase after 6 weeks of supplementation, with respect to GPX1 genotype. Data adjusted for age, sex, BMI, and baseline GPx1 activity. $p$ values for the ANCOVA/MANCOVA and contrast tests indicated in the figures

important antioxidant enzyme, which is responsible for reducing hydrogen peroxide in the presence of reduced glutathione [36]. Although GPx1 is Se-dependent enzyme, its activity relies also on other different factors, including age, sex, smoking status, and health condition [37-39]. To exclude the modifying effect of some of these variables, the study included only the non-smoking individuals who reported themselves to be free from chronic diseases, whereas sex and age were included in the analysis as covariates. Functional effects linked to GPX1 rs1050450 polymorphism, associated with proline (Pro)-to-leucine (Leu) substitution at codon 198 (or 200), were originally observed in MCF7 cells [35] and supported by some [27, 37, 40], though not all [41], human observational studies. Altogether, GPXI variant (Leu) allele has been suggested to cause lower responsiveness of GPx1 to Se. However, this hypothesis has not been entirely confirmed in human supplementation

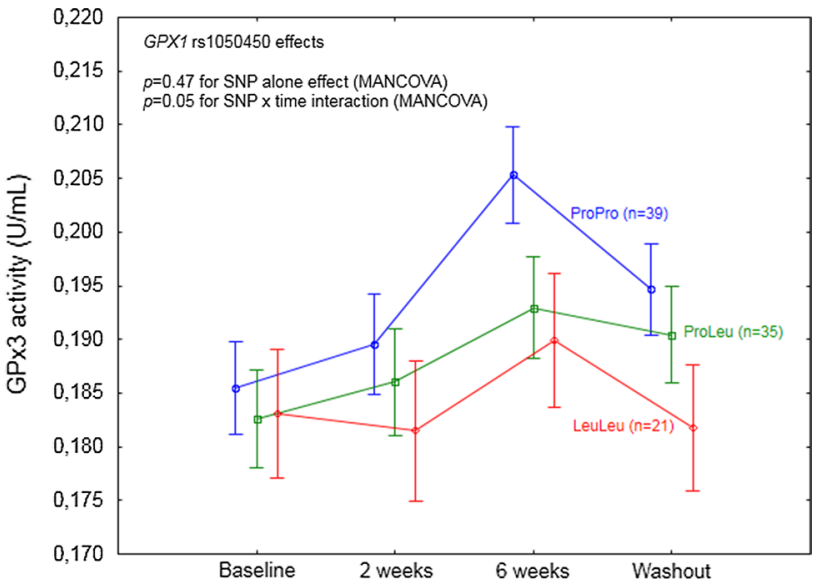

Fig. 2 GPX1 rs 1050450 effect on GPx3 activity in the individuals supplemented with selenium. A significant SNP effect was observed in the interaction with time. Data adjusted for age, sex, BMI, and baseline selenium. $p$ values for the MANCOVA indicated in the figure. According to the particular time points analysis, a significant difference in GPx3 activity as compared to baseline was shown after 6 weeks of supplementation and during the washout period for ProPro ( $p<0.0001$ and $p=0.002$, respectively) and ProLeu $(p=0.001$ and $p=0.02$, respectively)

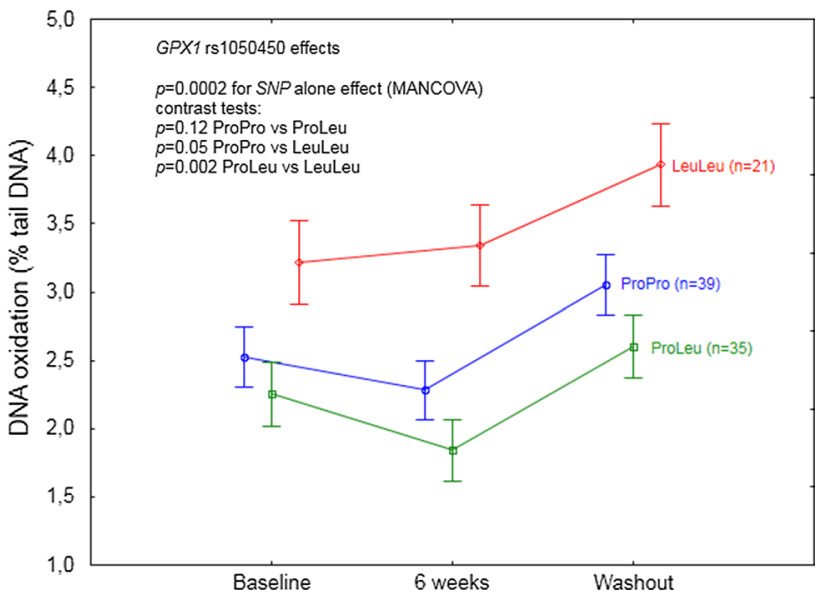

Fig. 3 GPX1 rs 1050450 effect on DNA oxidation (expressed as \% of DNA in comet tail) in the individuals supplemented with selenium. A significant SNP effect was observed regardless of time. Data adjusted for age, sex, BMI, and baseline selenium. $p$ values for the MANCOVA and contrast test indicated in the figure

trials. Miller et al. [24] combined the results of two separate randomized, placebo-controlled double-blind trials (RCT), in which subjects $(n=255)$ with coronary artery disease were supplemented with $100 \mu \mathrm{g}$ of Se (as SeMet) per day for 12 weeks. Average increase in GPx1 activity in the patients with at least one Leu allele was significantly lower as compared to ProPro homozygotes, but the difference between the genotypes was most evident in the subjects with 


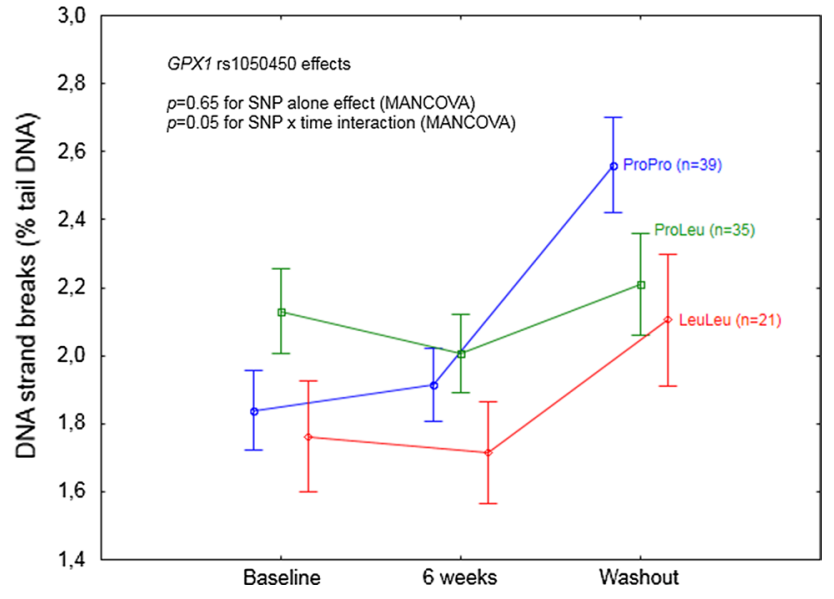

Fig. 4 GPX1 rs1050450 effect on DNA strand breaks (expressed as $\%$ of DNA in comet tail) in the individuals supplemeted with selenium. A significant SNP effect was observed in the interaction with time. Data adjusted for age, sex, BMI, and baseline selenium. $p$ values for the MANCOVA indicated in the figure. According to the particular time point analysis, a significant difference in DNA strand breaks as compared to baseline was shown during washout for ProPro homozygotes, $p<0.0001$

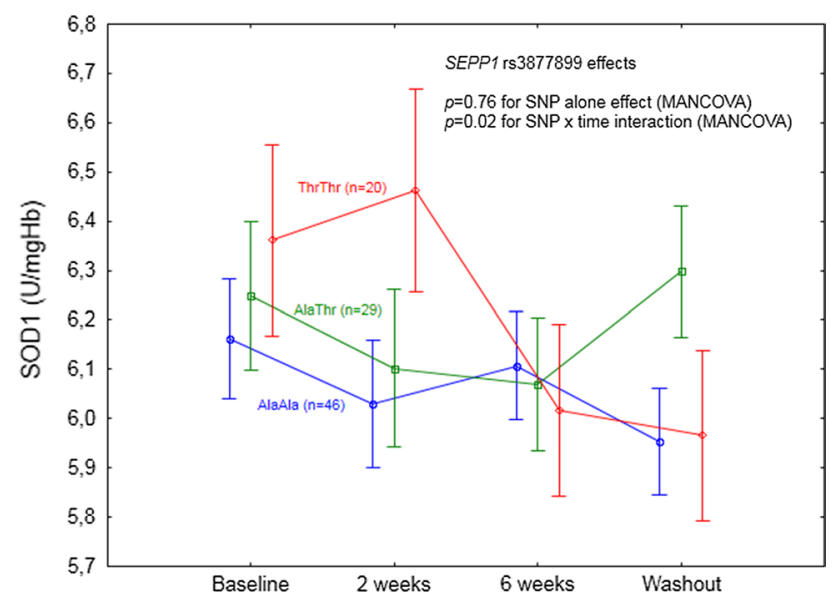

Fig. 5 SEPP1 rs3877899 effect on SOD1 activity in the individuals supplemented with selenium. A significant SNP effect was observed in the interaction with time. Data adjusted for age, sex, BMI, and baseline selenium. $p$ values for the MANCOVA indicated in the figure. According to the particular time point analysis, a significant difference in GPx3 activity as compared to baseline was shown for AlaAla homozygotes during washout $(p=0.04)$

the lowest baseline plasma Se concentration $(83-99 \mu \mathrm{g} / \mathrm{L})$. The second, smaller study was conducted among 37 obese women considered as Se-deficient (with the mean baseline plasma Se concentrations in different genotype groups ranging from 54 to $62 \mu \mathrm{g} / \mathrm{L}$ ), who were supplemented with Brazil nuts for 8 weeks (providing $290 \mu \mathrm{g}$ of Se/day) [25]. The authors have observed different magnitude of GPx1 activity increase depending on GPXI genotype; however, the difference was not statistically significant, possibly due to the low sample size (only five LeuLeu homozygotes). Our study, which was conducted among individuals with a relatively low baseline Se status (mean plasma Se $62.6 \mu \mathrm{g} / \mathrm{L}$ ), provides final evidence, indicating that GPX1 Leu allele at rs 1050450 is associated with a lower GPx1 response to $\mathrm{Se}$ supplementation, specifically in the individuals with low $\mathrm{Se}$ dietary intake. This observation excludes the utility of GPx1 activity as a useful biomarker of Se status in supplementation trials, not only in the high Se status but also among the low Se status population, as previously suggested by us [27]. Furthermore, we also observed that GPXI rs 1050450 polymorphism modulated the response of other peroxidase, GPx3, showing no enzyme responsiveness in the case of Leu homozygotes, after 6 weeks of supplementation. Because this SNP effect was not target related, the exact relationship remains unclear, though possibly resulting from strong redox-related interactions between both (erythrocyte and plasma) glutathione peroxidases.

\section{Unclear association between GPX1 polymorphism, Se supplementation, and DNA damage during washout}

On the basis of their study, Miller et al. [24] have concluded that individuals possessing Leu allele(s) have a higher demand for Se compared to ProPro homozygotes, suggesting that they may especially benefit from Se supplementation in terms of a decreased risk of cancer or other diseases. This hypothesis, though being very promising in terms of personalized nutrition, has never been verified by human long-term supplementation trials, and furthermore, human gene association studies indicate for a rather unclear relationship between GPXI polymorphism and cancer (detailed review in [42]). Following the hypothesis considering antioxidant activity of selenoproteins as one of the anticancer mechanisms exerted by Se, it is surprising that only few authors have investigated the relationship between GPx1 activity and any disease risk in a prospective manner. To our knowledge, only two such studies have been conducted, indicating significant inverse correlations in breast cancer [43] or coronary artery disease [44]. Thus, it should be noted that even though the possible relationship between GPX1 polymorphism and the risk of cancer may exist, there is no epidemiological evidence that GPx 1 upregulation caused specifically by $\mathrm{Se}$ supplementation may decrease such a risk, and that such supplementation should be especially beneficial in GPXI LeuLeu individuals with a low Se status. Some insights into a possible beneficial effect of Se supplementation specifically in GPXI LeuLeu individuals may be obtained by the analysis of the relationship between GPX1 rs1050450 polymorphism and cancer risk-related biomarkers, such as DNA damage, in the Se supplemented individuals. Such an analysis, so far, 
has been conducted only in two human supplementation trials. Caple et al. [22] analyzed the effect of GPX1 polymorphism on DNA damage (as assessed by comet assay) in blood lymphocytes of 48 subjects receiving $100 \mu \mathrm{g}$ of Se (in the form of antioxidant supplement containing also vitamins A, E, and C) for 6 weeks. No modifying effects of this SNP have been observed, either at the level of endogenous DNA damage, or at the level of peroxide-induced DNA damage (as expressed by percent of DNA in comet tail). In contrast, a significant effect of GPX1 polymorphism at the level of DNA damage has been observed in Brazil obese women in the already mentioned study, indicating that after 8 weeks of Brazil nuts consumption, ProPro homozygotes $(n=18)$ had lower DNA damage (measured by comet length), as compared to the baseline. Surprisingly, LeuLeu homozygotes $(n=5)$ apparently did not benefit from the supplementation, having significantly higher DNA damage after 8 weeks as compared to the wild-type homozygotes [25]. In our study, we observed that Se supplementation had no effect on DNA damage (regardless of the baseline values, as assessed in the MANCOVA model) but, intriguingly, the levels of both DNA oxidation and DNA strand breaks were significantly increased as compared to baseline, after 4 weeks following discontinuation of supplementation. Notably, this specific time point was during (not after) washout, as both plasma Se and Sepp1 markers (being significantly increased by intervention) still remained high. LeuLeu homozygotes had a significantly higher level of DNA oxidation as compared to ProPro and ProLeu subjects, which could be linked to the lower GPx1 activity as compared to ProPro or ProLeu; however, these genotype differences in DNA oxidation were independent of time, clearly indicating that GPx 1 increase caused by Se supplementation did not improve DNA repair specifically in LeuLeu homozygotes (nor did it in two other genotypes). Furthermore, considering DNA oxidation, the LeuLeu individuals seemed also to be the most negatively affected after supplementation discontinuation. In contrast, specifically ProPro homozygotes seemed to be the only genotype which was negatively affected by Se supplementation discontinuation at the level of DNA strand breaks, notwithstanding with the observation from the Brazil study (showing ProPro homozygotes to have decreased DNA damage after consumption of high Se content nuts) or with the observational study in New Zealanders in whom the lower DNA damage as a function of increasing serum Se level has been shown in ProPro homozygotes, but not in the ProLeu or LeuLeu subjects $[23,25]$. Nevertheless, we failed to indicate that GPX1 LeuLeu homozygotes may especially benefit from Se supplementation in terms of decreased DNA damage, which is consistent with the observed DNA damage effect in the LeuLeu subjects from the Brazil study [25]. Instead, we observed that GPX1 polymorphism modulated a specific negative "withdrawal effect" linked to Se supplementation discontinuation.

The overall observation of increased DNA damage during washout (shown regardless genotype) was somewhat unexpected and points to unrecognized properties of Se that may be assigned to specific chemical forms of Se present in Se yeast. The composition of Se yeast largely depends on the supplier [45], and considering that different chemical forms of Se have different cytotoxic and biochemical effects [46], it may not be excluded that some forms of Se exert deleterious effects on genomic stability. Blessing et al. indicated for example that reducible Se compounds such as phenylseleninic acid, phenylselenyl chloride, selenocystine, ebselen, and 2-nitrophenylselenocyanate are able to affect zinc finger proteins involved in DNA repair [47].

\section{Se supplementation was associated with overlapped prooxidant and antioxidant effects, accompanied by selective suppression of selenoprotein mRNA expression}

Considering daily dietary intake in Polish population $(20-59 \mu \mathrm{g})$, the average daily intake of the element in this study during supplementation should have not exceeded the upper tolerable limits of 300 or $400 \mu \mathrm{g} / \mathrm{day}$, set by the European Scientific Committee on Food or US Food and Nutrition Board [4, 48]; thus, no toxic effects were expected. Furthermore, post-supplementation plasma Se concentrations in the study individuals $(55-149 \mu \mathrm{g} / \mathrm{L})$ were close to or lower than those reported in plasma or serum in other short-term Se supplementation trials, such as SELGEN (109 $\mu \mathrm{g} / \mathrm{L}$, plasma), Danish study (126-154 $\mu \mathrm{g} / \mathrm{L}$, serum), New Zealand study (142.1 $\mu \mathrm{g} / \mathrm{L}$, plasma), or Brazil study (127-148 $\mu \mathrm{g} / \mathrm{L}$, plasma) [21, 24, 25, 49], and notably, it was even lower than presupplementation values observed in the long-term supplementation trials such as NPC $(114 \mu \mathrm{g} / \mathrm{L}$, plasma) or SELECT $(135 \mu \mathrm{g} / \mathrm{L}$, serum $)$ $[13,50]$. However, we observed that Se supplementation was associated with a significant increase in lipid peroxidation, which occurred already after 2 weeks of intervention and which did not diminish after 4 weeks of washout. This prooxidant effect was accompanied by the overall increased ability to challenge oxidative stress (as indicated by higher activities of GPx 1, GPx3, Cp, and higher plasma antioxidant capacity), suggesting some overlapped antioxidant and prooxidant processes, possibly resulting from the overlapped activity of different Se compounds present in Se yeast [45]. At the same time, mRNA expression in white blood cells (WBC) for five selenoprotein-encoding genes (GPX1, GPX4, SEP15, SELS, and SELW) was significantly decreased, suggesting that such a negative transcriptional feedback could have been induced by excess of Se. In other 
words, additional intake of $200 \mu \mathrm{g}$ of Se may be considered too high in the study group. Selenoprotein mRNA expression in WBC has been proposed as a potential marker of Se status [51, 52]. However, studies conducted in humans point to no correlation between selenoprotein gene expression in blood and plasma/serum Se in the subjects supposed to be already Se repleted or possessing relatively high baseline Se status [49, 52, 53]. In contrast, Pagmantidis et al. [54] have observed a subtle increase in mRNA expression for SPS1, SEP15, and SELK in the individuals with baseline plasma $\mathrm{Se}=93.9 \mu \mathrm{g} / \mathrm{L}(n=39$, $)$ who were supplemented with selenate for 6 weeks. The only study which is partially consistent with our results is a 12-week Se supplementation trial joined with trivalent influenza vaccination at week 10th. In the trial, 119 non-smoking men (age 50-64 years) with the mean plasma Se concentration of $95.5 \mu \mathrm{g} / \mathrm{L}$ were supplemented with $\mathrm{Se}$ in a form of Se yeast $(50,100$, or $200 \mu \mathrm{g} / \mathrm{day})$ or Se-enriched onions $(50 \mu \mathrm{g})$, and a significant decrease in mRNA expression has been observed after 10 weeks of supplementation (before vaccination) for $S E L W$ in the highest Se dose group (200 $\mu \mathrm{g} /$ day Se yeast) as compared to the placebo. For the two other analyzed selenoproteins (SELS and SELR), no changes in mRNA expression have been reported during Se supplementation (before vaccination) [55]. Notably, both SELW and SELS were decreased upon Se supplementation in our study. Altogether, the effect of Se intervention on mRNA selenoprotein expression in humans seems to be selective and possibly depends on the chemical form of Se (as supported by in vitro study [56]) as well as on the baseline Se status. Our study, which was conducted among the subjects with the lowest baseline Se status, as compared to other trials discussed indicated that a high dose intervention in the subjects with a relatively low dietary intake induced selective selenoprotein mRNA decrease. One cannot exclude that this negative transcriptional feedback resulted from a specific redox dysregulation linked to a too high difference in the redox state between presupplementation and (post) supplementation period, which consequently prevented the adaptation process to occur. This hypothesis seems in line with the new concept of reductive stress, which may be induced by upregulated GPx1 activity [42].

\section{Minor effect of SEPP1 rs3877899 polymorphism}

The second SNP of interest in this study, SEPPI rs3877899, associated with the alanine (Ala) into threonine (Thr) change in the polypeptide chain at codon 234, was shown to affect expression of different Sepp1 isoforms, showing that variant (Thr) allele is associated with lower proportions of $60-\mathrm{kDa}$ isoform, and that plasma Sepp1 concentration may depend on the interaction between this SNP and sex $[21,57]$. In our study, we failed to find any effect of SEPP1 polymorphism on Sepp1, either at the level of protein or mRNA. However, we observed that the SNP affected plasma Se concentration at baseline, with the lower levels in the subjects possessing Thr allele(s), and this effect was also observed during a supplementation trial at the level approaching statistical significance $(p=0.08)$. Meplan et al. have observed that SEPPI polymorphism modified the levels of plasma $\mathrm{Se}$ in a response to supplementation in BMI-dependent manner, suggesting that SEPPI may affect response to Se specifically in the individuals with higher BMI (higher than 30). In this study, as assessed by MANCOVA model, we failed to find such an interaction, possibly due to the small number of individuals with BMI higher than 30 (no BMI effects on plasma Se response were observed, either alone or in combination with SEPP1 genotype, data not shown). Meplan et al. have observed several other, not target related, effects of SEPP1 rs3877899 polymorphism, linked to the affected expression or activity of specific selenoproteins in blood compartments (TRxR1, GPx1, or GPx4). The authors have concluded that different expression of Sepp1 associated with SEPP1 rs3877899 polymorphism may affect expression and activities of other selenoproteins by influencing $\mathrm{Se}$ supply to different tissues. In our study, such effects were minor and they concerned combined and time-dependent effect of GPX1 and SEPP1 polymorphisms on SEP15 expression, which may reflect the complexity of interactions within human selenoproteome, pointing to its dependence on Se supply and Se-dependent redox regulation. The other SEPPI effect, observed in the interaction with time and linked to the activity of Se-independent antioxidant enzyme, superoxide dismutase 1 , was rather not consistent and difficult to explain, though it may confirm some metabolic link between Sepp1 expression and redox pathway related to glutathione peroxidases as a product of SOD1 (hydrogen peroxide) is a substrate for GPx1 and GPx3.

\section{Study limitations}

The major limitation of the study concerns multiple testing, which could have generated false associations. Indeed, after the false discovery rate analysis was conducted, most of the observed effects were no more statistically significant. However, the most significant effects (relationship between GPX1 polymorphism and GPx1 activity as well as DNA oxidation) were in line with the previous hypotheses and observations. Other limitation of the study is associated with the fact that the study was not randomized as the subjects were selected according to the genotype, and the genotype distribution in the study group was not representative of the whole population. However, since we especially aimed at analyzing the effects of minor alleles, such 
selection seems to be justified. Finally, the reported results were not further confirmed by an independent replication analysis and need to be verified.

\section{Conclusions}

Lack of beneficial effects of Se supplementation in the individuals with a relatively low Se status, as indicated in this study at the level of DNA damage, does not provide molecular basis for the hypothesis on anticancer activity of the element in the populations with its low dietary intake. Overall, our study confirmed the functional effect of GPXI rs1050450 polymorphism linked to the lower GPx1 activity response to Se supplementation; however, it did not support the hypothesis that individuals possessing $G P X 1$ variant allele(s) may especially benefit from the increased Se intake. Findings linked to the suppressed mRNA expression of selected selenoproteins and prooxidant effects observed during supplementation warrant further investigation, whereas observation of the increased DNA damage during washout may give further insights into the unclear relationship between DNA damage and Se [47, 58]. Intriguingly, the possible modifying effect of GPXI polymorphism on DNA damage during washout may shift the current interest of genetic profiling of selenoproteins from question "who may benefit from Se supplementation," into "who may be less harmed by such a kind of intervention."

Acknowledgments We acknowledge National Science Centre (Grant 1666/B/P01/2011/40) and the Nofer Institute of Occupational Medicine (Internal Grant IMP 1.13/2013-2014).

\begin{abstract}
Authors' contributions EJ designed the study and performed SNP genotyping, ER supervised all molecular genetic analyses and design gene expression experiment, SR performed statistical analysis, JG analyzed plasma for Sepp1 concentration and supervised all biochemical analyses, EW performed gene expression experiments, MBK collected blood and questionnaire data from the subjects and performed selected biochemical analyses, ASP and MS performed comet assay, $\mathrm{MN}$ performed oxidative burst analysis, KS analyzed plasma for selenium concentration, WW and MHB supplied materials and reagents, EJ wrote the manuscript. All the authors have read and accepted the final version of the manuscript.
\end{abstract}

Compliance with ethics guidelines All the procedures performed in the studies involving human participants were in accordance with the ethical standards of the Institutional and/or National Research Committee and with the 1964 Helsinki declaration and its later amendments or comparable ethical standards.

Conflict of interest On behalf of all authors, the corresponding author states that there is no conflict of interest.

Open Access This article is distributed under the terms of the Creative Commons Attribution 4.0 International License (http://creativecommons.org/licenses/by/4.0/), which permits unrestricted use, distribution, and reproduction in any medium, provided you give appropriate credit to the original author(s) and the source, provide a link to the Creative Commons license, and indicate if changes were made.

\section{References}

1. Hatfield DL, Tsuji PA, Carlson BA, Gladyshev VN (2014) Selenium and selenocysteine: roles in cancer, health, and development. Trends Biochem Sci 39:112-120. doi:10.1016/j. tibs.2013.12.007

2. Labunskyy VM, Hatfield DL, Gladyshev VN (2014) Selenoproteins: molecular pathways and physiological roles. Physiol Rev 94:739-777. doi:10.1152/physrev.00039.2013

3. Jukes TH (1983) Selenium, an "essential poison". J Appl Biochem 5:233-234

4. Otten JJ, Hellwig JP, Meyers LD (2006) Dietary reference intakes: the essential guide to nutrient requirements. National Academy Press, Washington

5. Efsa, NDA Panel (2014) Scientific opinion on dietary reference values for selenium. EFSA J 12:1-67. doi:10.2903/j.efsa.2014. NNNN

6. Hurst R, Collings R, Harvey LJ, King M, Hooper L, Bouwman J, Gurinovic M, Fairweather-Tait SJ (2013) EURRECA-estimating selenium requirements for deriving dietary reference values. Crit Rev Food Sci Nutr 53:1077-1096. doi:10.1080/10408398.2012.74 2861

7. Rayman MP (2012) Selenium and human health. Lancet 379:1256-1268. doi:10.1016/S0140-6736(11)61452-9

8. Vinceti M, Dennert G, Crespi CM, Zwahlen M, Brinkman M, Zeegers MP, Horneber M, D'Amico R, Del Giovane C (2014) Selenium for preventing cancer. Cochrane Database Syst Rev 3:CD005195. doi:10.1002/14651858.CD005195.pub3

9. Letavayova L, Vlckova V, Brozmanova J (2006) Selenium: from cancer prevention to DNA damage. Toxicology 227:1-14. doi:10.1016/j.tox.2006.07.017

10. Fernandes AP, Gandin V (2014) Selenium compounds as therapeutic agents in cancer. Biochim Biophys Acta. doi:10.1016/j. bbagen.2014.10.008

11. Hatfield DL, Yoo MH, Carlson BA, Gladyshev VN (2009) Selenoproteins that function in cancer prevention and promotion. Biochim Biophys Acta 1790:1541-1545. doi:10.1016/j. bbagen.2009.03.001

12. Davis CD, Tsuji PA, Milner JA (2012) Selenoproteins and cancer prevention. Annu Rev Nutr 32:73-95. doi:10.1146/ annurev-nutr-071811-150740

13. Lippman SM, Klein EA, Goodman PJ, Lucia MS, Thompson IM, Ford LG, Parnes HL, Minasian LM, Gaziano JM, Hartline JA, Parsons JK, Bearden JD 3rd, Crawford ED, Goodman GE, Claudio J, Winquist E, Cook ED, Karp DD, Walther P, Lieber MM, Kristal AR, Darke AK, Arnold KB, Ganz PA, Santella RM, Albanes D, Taylor PR, Probstfield JL, Jagpal TJ, Crowley JJ, Meyskens FL Jr, Baker LH, Coltman CA Jr (2009) Effect of selenium and vitamin $\mathrm{E}$ on risk of prostate cancer and other cancers: the Selenium and Vitamin E Cancer Prevention Trial (SELECT). JAMA 301:39-51. doi:10.1001/ jama.2008.864

14. Rayman MP, Stranges S (2013) Epidemiology of selenium and type 2 diabetes: Can we make sense of it? Free Radic Biol Med 65:1557-1564. doi:10.1016/j.freeradbiomed.2013.04.003

15. Rocourt CR, Cheng WH (2013) Selenium supranutrition: are the potential benefits of chemoprevention outweighed by the promotion of diabetes and insulin resistance? Nutrients 5:1349-1365. doi:10.3390/nu5041349

16. Rayman MP (2009) Selenoproteins and human health: insights from epidemiological data. Biochim Biophys Acta 1790:15331540. doi:10.1016/j.bbagen.2009.03.014

17. Meplan C, Hesketh J (2014) Selenium and cancer: a story that should not be forgotten-insights from genomics. Cancer Treat Res 159:145-166. doi:10.1007/978-3-642-38007-5_9 
18. Saito Y, Hayashi T, Tanaka A, Watanabe Y, Suzuki M, Saito E, Takahashi K (1999) Selenoprotein P in human plasma as an extracellular phospholipid hydroperoxide glutathione peroxidase. Isolation and enzymatic characterization of human selenoprotein P. J Biol Chem 274:2866-2871

19. Labunskyy VM, Hatfield DL, Gladyshev VN (2014) Selenoproteins: molecular pathways and physiological roles. Physiol Rev 94:739-777. doi:10.1152/physrev.00039.2013

20. Arteel GE, Mostert V, Oubrahim H, Briviba K, Abel J, Sies H (1998) Protection by selenoprotein P in human plasma against peroxynitrite-mediated oxidation and nitration. Biol Chem 379:1201-1205

21. Meplan C, Crosley LK, Nicol F, Beckett GJ, Howie AF, Hill KE, Horgan G, Mathers JC, Arthur JR, Hesketh JE (2007) Genetic polymorphisms in the human selenoprotein $\mathrm{P}$ gene determine the response of selenoprotein markers to selenium supplementation in a gender-specific manner (the SELGEN study). FASEB J 21:3063-3074. doi:10.1096/fj.07-8166com

22. Caple F, Williams EA, Spiers A, Tyson J, Burtle B, Daly AK, Mathers JC, Hesketh JE (2010) Inter-individual variation in DNA damage and base excision repair in young, healthy nonsmokers: effects of dietary supplementation and genotype. Br J Nutr 103:1585-1593. doi:10.1017/S0007114509993540

23. Karunasinghe N, Han DY, Zhu S, Yu J, Lange K, Duan H, Medhora R, Singh N, Kan J, Alzaher W, Chen B, Ko S, Triggs CM, Ferguson LR (2012) Serum selenium and single-nucleotide polymorphisms in genes for selenoproteins: relationship to markers of oxidative stress in men from Auckland, New Zealand. Genes Nutr 7:179-190. doi:10.1007/s12263-011-0259-1

24. Miller JC, Thomson CD, Williams SM, van Havre N, Wilkins GT, Morison IM, Ludgate JL, Skeaff CM (2012) Influence of the glutathione peroxidase 1 Pro200Leu polymorphism on the response of glutathione peroxidase activity to selenium supplementation: a randomized controlled trial. Am J Clin Nutr 96:923-931. doi:10.3945/ajcn.112.043125

25. Cominetti C, de Bortoli MC, Purgatto E, Ong TP, Moreno FS, Garrido AB Jr, Cozzolino SM (2011) Associations between glutathione peroxidase-1 Pro198Leu polymorphism, selenium status, and DNA damage levels in obese women after consumption of Brazil nuts. Nutrition 27:891-896. doi:10.1016/j. nut.2010.09.003

26. Jablonska E, Gromadzinska J, Klos A, Bertrandt J, Skibniewska K, Darago A, Wasowicz W (2013) Selenium, zinc and copper in the Polish diet. JFCA 31:259-265. doi:10.1016/j. jfca.2013.05.016

27. Jablonska E, Gromadzinska J, Reszka E, Wasowicz W, Sobala W, Szeszenia-Dabrowska N, Boffetta P (2009) Association between GPx1 Pro198Leu polymorphism, GPx1 activity and plasma selenium concentration in humans. Eur J Nutr 48:383386. doi:10.1007/s00394-009-0023-0

28. Paglia DE, Valentine WN (1967) Studies on the quantitative and qualitative characterization of erythrocyte glutathione peroxidase. J Lab Clin Med 70:158-169

29. Beauchamp C, Fridovich I (1971) Superoxide dismutase: improved assays and an assay applicable to acrylamide gels. Anal Biochem 44:276-287

30. Sunderman FW Jr, Nomoto S (1970) Measurement of human serum ceruloplasmin by its p-phenylenediamine oxidase activity. Clin Chem 16:903-910

31. Wasowicz W, Neve J, Peretz A (1993) Optimized steps in fluorometric determination of thiobarbituric acid-reactive substances in serum: importance of extraction $\mathrm{pH}$ and influence of sample preservation and storage. Clin Chem 39:2522-2526

32. Singh NP, McCoy MT, Tice RR, Schneider EL (1988) A simple technique for quantitation of low levels of DNA damage in individual cells. Exp Cell Res 175:184-191
33. McKelvey-Martin VJ, Green MH, Schmezer P, Pool-Zobel BL, De Meo MP, Collins A (1993) The single cell gel electrophoresis assay (comet assay): a European review. Mutat Res 288:47-63

34. Collins AR, Duthie SJ, Dobson VL (1993) Direct enzymic detection of endogenous oxidative base damage in human lymphocyte DNA. Carcinogenesis 14:1733-1735

35. Hu YJ, Diamond AM (2003) Role of glutathione peroxidase 1 in breast cancer: loss of heterozygosity and allelic differences in the response to selenium. Cancer Res 63:3347-3351

36. Brigelius-Flohe R, Maiorino M (2013) Glutathione peroxidases. Biochim Biophys Acta 1830:3289-3303. doi:10.1016/j. bbagen.2012.11.020

37. Malling TH, Sigsgaard T, Andersen HR, Frischknecht L, Deguchi Y, Skadhauge L, Sherson D, Thomsen G, Baelum J, Pedersen JK, Omland O (2009) Sex determines the influence of smoking and gene polymorphism on glutathione peroxidase activity in erythrocytes. Scand J Clin Lab Invest 69:295-302. doi:10.1080/00365510802632155

38. Andersen HR, Nielsen JB, Nielsen F, Grandjean P (1997) Antioxidative enzyme activities in human erythrocytes. Clin Chem 43:562-568

39. Saraymen R, Kilic E, Yazar S, Cetin M (2003) Influence of sex and age on the activity of antioxidant enzymes of polymorphonuclear leukocytes in healthy subjects. Yonsei Med J 44:9-14

40. Hansen RD, Krath BN, Frederiksen K, Tjonneland A, Overvad K, Roswall N, Loft S, Dragsted LO, Vogel U, Raaschou-Nielsen O (2009) GPX1 Pro(198)Leu polymorphism, erythrocyte GPX activity, interaction with alcohol consumption and smoking, and risk of colorectal cancer. Mutat Res 664:13-19. doi:10.1016/j. mrfmmm.2009.01.009

41. Forsberg L, de Faire U, Marklund SL, Andersson PM, Stegmayr B, Morgenstern R (2000) Phenotype determination of a common Pro-Leu polymorphism in human glutathione peroxidase 1 . Blood Cells Mol Dis 26:423-426. doi:10.1006/bcmd.2000.0325

42. Lubos E, Loscalzo J, Handy DE (2011) Glutathione peroxidase-1 in health and disease: from molecular mechanisms to therapeutic opportunities. Antioxid Redox Signal 15:1957-1997. doi:10.1089/ars.2010.3586

43. Ravn-Haren G, Olsen A, Tjonneland A, Dragsted LO, Nexo BA, Wallin H, Overvad K, Raaschou-Nielsen O, Vogel U (2006) Associations between GPX1 Pro198Leu polymorphism, erythrocyte GPX activity, alcohol consumption and breast cancer risk in a prospective cohort study. Carcinogenesis 27:820-825. doi:10.1093/carcin/bgi267

44. Blankenberg S, Rupprecht HJ, Bickel C, Torzewski M, Hafner G, Tiret L, Smieja M, Cambien F, Meyer J, Lackner KJ (2003) Glutathione peroxidase 1 activity and cardiovascular events in patients with coronary artery disease. N Engl J Med 349:16051613. doi:10.1056/NEJMoa030535

45. Larsen EH, Hansen M, Paulin H, Moesgaard S, Reid M, Rayman M (2004) Speciation and bioavailability of selenium in yeastbased intervention agents used in cancer chemoprevention studies. J AOAC Int 87:225-232

46. Hoefig CS, Renko K, Kohrle J, Birringer M, Schomburg L (2011) Comparison of different selenocompounds with respect to nutritional value vs. toxicity using liver cells in culture. J Nutr Biochem 22:945-955. doi:10.1016/j.jnutbio.2010.08.006

47. Blessing H, Kraus S, Heindl P, Bal W, Hartwig A (2004) Interaction of selenium compounds with zinc finger proteins involved in DNA repair. Eur J Bioch 271:3190-3199. doi:10.1111/j.1432-1033.2004.04251.x

48. SCF (2000) Opinion of the scientific committee on food on the tolerable upper intake level of selenium. European Commission, Luxembourg

49. Ravn-Haren G, Bugel S, Krath BN, Hoac T, Stagsted J, Jorgensen $\mathrm{K}$, Bresson JR, Larsen EH, Dragsted LO (2008) A short-term 
intervention trial with selenate, selenium-enriched yeast and selenium-enriched milk: effects on oxidative defence regulation. Br J Nutr 99:883-892. doi:10.1017/S0007114507825153

50. Clark LC, Combs GFJ, Turnbull BW, Slate EH, Chalker DK, Chow J, Davis LS, Glover RA, Graham GF, Gross EG, Krongrad A, Lesher JLJ, Park HK, Sanders BBJ, Smith CL, Taylor JR, Nutritional Prevention of Cancer Study Group (1996) Effects of selenium supplementation for cancer prevention in patients with carcinoma of the skin. A randomized controlled trial. JAMA 276:1957-1963

51. Sunde RA (2010) mRNA transcripts as molecular biomarkers in medicine and nutrition. J Nutr Biochem 21:665-670. doi:10.1016/j. jnutbio.2009.11.012

52. Reszka E, Jablonska E, Gromadzinska J, Wasowicz W (2012) Relevance of selenoprotein transcripts for selenium status in humans. Genes Nutr 7:127-137. doi:10.1007/s12263-011-0246-6

53. Sunde RA, Paterson E, Evenson JK, Barnes KM, Lovegrove JA, Gordon MH (2008) Longitudinal selenium status in healthy British adults: assessment using biochemical and molecular biomarkers. Br J Nutr 99(Suppl 3):S37-S47. doi:10.1017/ S0007114508006831

54. Pagmantidis V, Meplan C, van Schothorst EM, Keijer J, Hesketh JE (2008) Supplementation of healthy volunteers with nutritionally relevant amounts of selenium increases the expression of lymphocyte protein biosynthesis genes. Am J Clin Nutr 87:181-189

55. Goldson AJ, Fairweather-Tait SJ, Armah CN, Bao Y, Broadley MR, Dainty JR, Furniss C, Hart DJ, Teucher B, Hurst R (2011) Effects of selenium supplementation on selenoprotein gene expression and response to influenza vaccine challenge: a randomised controlled trial. PLoS One 6:e14771. doi:10.1371/journal.pone. 0014771

56. Kipp AP, Frombach J, Deubel S, Brigelius-Flohe R (2013) Selenoprotein $\mathrm{W}$ as biomarker for the efficacy of selenium compounds to act as source for selenoprotein biosynthesis. Methods Enzymol 527:87-112. doi:10.1016/ B978-0-12-405882-8.00005-2

57. Meplan C, Nicol F, Burtle BT, Crosley LK, Arthur JR, Mathers JC, Hesketh JE (2009) Relative abundance of selenoprotein $\mathrm{P}$ isoforms in human plasma depends on genotype, se intake, and cancer status. Antioxid Redox Signal 11:2631-2640. doi:10.1089/ARS.2009.2533

58. Karunasinghe N, Han DY, Zhu S, Duan H, Ko YJ, Yu JF, Triggs CM, Ferguson LR (2013) Effects of supplementation with selenium, as selenized yeast, in a healthy male population from New Zealand. Nutr Cancer 65:355-366. doi:10.1080/01635581.2013. 760743 